\title{
CYTOTOXICITY AND ANTIOXIDANT ACTIVITY OF PLANT EXTRACTS FROM VIETNAM
}

\author{
Nguyen Thi Mai Phuong ${ }^{1,2,}$, Christin Boger ${ }^{3}$, Ulrike Lindequist ${ }^{3}$ \\ ${ }^{1}$ Institute of Biotechnology, VAST, Vietnam \\ ${ }^{2}$ Graduate University of Science and Technolog, VAST, Vietnam \\ ${ }^{3}$ University of Greifswald, Germany
}

Received 14 September 2019, accepted 18 January 2020

\begin{abstract}
Traditional medicine plays an important role in treatment of human diseases. Extracts from medicinal plants exhibit many valuable biological activities. However, the exploitation and application of the extracts requires knowlege on the mechanism of action. In this study, cytotoxic and antioxidant activites of the methanol and hexane extracts of 09 Vietnamese plants have been studied in vitro on keratinocyte $\mathrm{HaCaT}$ cell line. The results showed that all plant extracts had a cytotoxyc effect on HaCaT cells. The hexane extracts showed more potent than the methanol extract. Garcinia mangostana exhibited the best cytotoxicity with $\mathrm{IC}_{50}$ values of $14.42 \mu \mathrm{g} / \mathrm{ml}$ (for hexane extract) và $14.27 \mu \mathrm{g} / \mathrm{ml}$ (for $\mathrm{MeOH}$ extract). All tested extracts resulted in the generation of intracellular reactive oxygen radicals in HaCaT cells. Mangifera indica, Cleistocalyx operculatus and Terminalia catappa had the best DPPH radical scavenging activity with $\mathrm{EC}_{50}$ values of $23.0 \mu \mathrm{g} / \mathrm{ml}, 27.4 \mu \mathrm{g} / \mathrm{ml}$ and $23.73 \mu \mathrm{g} / \mathrm{ml}$, respectively. Besides, G. mangostana and T.catappa exhibited capacity of eliminating active oxygen radicals (iROS). The test extracts significantly reduced the number of cells in phase G1 and increased the number of cells in S and G2/M phases. The data obtained in this study are the preliminary results for further studies on the mechanisms of action and therapeutic applications of these plants.
\end{abstract}

Keywords: Antioxidant, cell cycle arrest, cytotoxycity, plant extracts, reactive oxygen species.

Citation: Nguyen Thi Mai Phuong, Boger C., Lindequist U., 2020. Cytotoxicity and antioxidant activity of plant extracts from Vietnam. Tap chi Sinh hoc, 42(1): 31-39. https://doi.org/10.15625/0866-7160/v42n1.14418.

*Corresponding author email: phuongnguyenibt@ gmail.com

(C2020 Vietnam Academy of Science and Technology (VAST) 


\title{
HOẠT TÍNH GÂY ĐộC TÊ BÀO VÀ CHỐNG OXI HÓA CỦA MộT SỐ DỊCH CHIẾT THỰC VẠTT Ở VIẸTT NAM
}

\author{
Nguyễn Thị Mai Phương ${ }^{1,2, *}$, Christin Boger ${ }^{3}$, Ulrike Lindequist ${ }^{3}$ \\ ${ }^{1}$ Viện Công nghệ sinh học, Viện Hàn lâm khoa học và Công nghệ Việt Nam \\ ${ }^{2}$ Học viện Khoa học và Công nghệ Việt Nam, Viện Hàn lâm khoa học và Công nghệ Việt Nam \\ ${ }^{3}$ Trường Đại học Greífswalf, CHLB Đức
}

Ngày nhận bài 14-9-2019, ngày chấp nhận 18-1-2020

\section{TÓM TẮT}

Các dịch chiết từ cây dược liệu chứa nhiều hoạt tính sinh học quý, có tác dụng chữa bệnh. Để làm cơ sở cho việc khai thác và sử dụng chúng cần nghiên cứu đầy đủ về hoạt tính và cơ chế tác động. Trong nghiên cứu này, hoạt tính gây độc tế bào và chống oxy hóa thông qua tác dụng triệt tiêu gốc tự do của các dịch chiết methanol và hexane của 9 loài thực vật ở Việt Nam đã được nghiên cứu in vitro trên dòng tế bào keratinocyte $\mathrm{HaCaT}$. Kết quả thu được cho thấy, các dịch chiết thực vật đều có có tác dụng gây độc tế bào $\mathrm{HaCaT}$. Các dịch chiết hexane có độc tính tế bào cao hơn so với dịch chiết methanol $(\mathrm{MeOH})$, trong đó dịch chiết Garcinia mangostana có độc tính tế bào mạnh nhất với giá trị $\mathrm{IC}_{50}$ đạt $14,42 \mu \mathrm{g} / \mathrm{ml}$ (hexane) và $14,27 \mu \mathrm{g} / \mathrm{ml}(\mathrm{MeOH})$. Tất cả các dịch chiết từ thực vật được thử nghiệm đều dẫn đến việc tạo ra các gốc oxy nội bào trong tế bào $\mathrm{HaCaT}$, là một trong những nguyên nhân gây độc tế bào. Dịch chiết từ Mangifera indica, Cleistocalyx operculatus và Terminalia catappa có hoạt tính triệt tiêu gốc tự do DPPH cao nhất với giá trị $\mathrm{EC}_{50}$ đạt tương ứng $23 \mu \mathrm{g} / \mathrm{ml} ; 27,4 \mu \mathrm{g} / \mathrm{ml}$ và $23,73 \mu \mathrm{g} / \mathrm{ml}$. Ngoài ra, dịch chiết của 2 loài G. mangostana và T. catappa còn có khả năng triệt tiêu gốc oxy hoạt động nội sinh (iROS). Tất cả các dịch chiết từ thực vật đều làm giảm đáng kể số lượng tế bào trong pha G1 và do đó, làm tăng số lượng tế bào trong các pha $\mathrm{S}$ và $\mathrm{G} 2 / \mathrm{M}$. Các số liệu thu được là cơ sở để tiếp tục các nghiên cứu sâu hơn về cơ chế tác dụng và ứng dụng của các thực vật này.

Từ khóa: chống oxy hóa, chu kỳ tế bào, dịch chiết thực vật, độc tính tế bào, oxy hoạt động.

*Địa chỉ liên hệ email: phuongnguyenibt@gmail.com

\section{MỞ ĐẦU}

Các dịch chiết từ các cây dược liệu có tác dụng chữa bệnh như kháng khuẩn, kháng viêm, kháng ung thư, chống oxy hóa, chống tiểu đường, vì vậy được sử dụng trong y học cổ truyền (Đỗ Tất Lợi, 1991). Các nguyên liệu thực vật chứa các chất thứ cấp có hoạt tính sinh học, để có thể phát triển thành thuốc và ứng dụng cần nghiên cứu đầy đủ về cơ chế tác động của các hoạt chất này.

Chất oxy hoá hay còn gọi là gốc tự do, là những phân tử hay hợp tử chất, có chứa điện tử không ghép đôi. Chính nhờ điện tử này mà gốc tự do có hoạt tính oxy hóa rất mạnh, thông qua việc lấy điện tử của chất nó phản ứng (để ghép đôi với điện tử chưa ghép cặp) và làm tổn thương chất bị nó oxy hoá. Phản ứng oxy hoá trong cơ thể là phản ứng của chất oxy hoá chứa gốc tự do gây phá huỷ tế bào (đặc biệt ở màng tế bào hoặc $\mathrm{ADN}$ trong nhân tế bào), gây tổn thương các mô, các tổ chức của cơ thể, đồng thời gây tắc nghẽn động mạch, phát triển các bệnh như ung thư, Alzheimer và nhiều bệnh lý khác khiến cơ thể lão hoá nhanh chóng và tử vong (Tandon \& Gupta, 2005). 
Trong chu kỳ tế bào, bộ máy di truyền và các thành phần của tế bào được nhân đôi và sau đó tế bào phân chia làm hai tế bào con. Trong các tế bào nhân chuẩn, chu kỳ tế bào bao gồm hai giai đoạn: giai đoạn kỳ trung gian là lúc tế bào phát triển, tích lũy vật chất và nhân đôi $A D N$ và giai đoạn nguyên phân (mitosis) và được chia thành các pha gồm: $\mathrm{G}_{1}$, $\mathrm{S}, \mathrm{G}_{2}$ (kỳ trung gian) và pha nguyên phân $(\mathrm{M})$. Tế bào nếu có chu kỳ bị tạm thời ngưng trệ hay bị đảo ngược thì được xem như lâm vào một trạng thái tĩnh lặng gọi là pha $\mathrm{G}_{0}$. Hai yếu tố then chốt có vai trò điều tiết chu kỳ tế bào là cyclin và kinase phụ thuộc vào cyclin (cyclin-dependent kinase - CDK) (Matsumoto et al., 2005).

Mục đích của bài báo này tập trung nghiên cứu ảnh hưởng của một số dịch chiết thực vật của Việt Nam, có hoạt tính sinh học, đã được dùng đề chữa bệnh trong dân gian (Abdullah et al., 2014; Abrahim et al., 2012; Behera et al., 2013; Dosoky et al., 2015; Li et al., 2007; Mahabusarakam et al., 2005; Saraiva et al., 2012; Padmapriya \& Poonguzhali, 2015; Wu et al., 2015; Đô̂ Tất Lợi, 1991). Tuy nhiên, những dịch chiết này chưa được nghiên cứu đầy đủ về hoạt tính gây độc tính tế bào và khả năng loại bỏ gốc tự do in vitro trên tế bào HaCaT để trả lời cho một số câu hỏi như: Các dịch chiết thực vật này có tác dụng gây độc tế bào keratinocyte $\mathrm{HaCaT}$ hay không và có hay không sự khác nhau về độc tính giữa dịch chiết methanol và hexane?; các đặc tính chống oxy hóa của các dịch chiết này có liên quan hay không đến sự cảm ứng của các loại oxy nội bào?; có hay không khả năng các dịch chiết methanol bắt giữ tể bào ở giai đoạn giữa chu kỳ tế bào?. Trả lời được các câu hỏi này sẽ là dẫn liệu cơ bản cho những nghiên cứu sâu hơn về cơ chế tác dụng và ứng dụng của các dịch chiết từ thực vật.

\section{VÂT LIỆU VÀ PHƯƠNG PHÁP NGHIÊN CƯUU}

Vật liệu là dòng tế bào biểu mô tự nhiên, bất tử keratinocyte $\mathrm{HaCaT}$ ở người. Đây là tế bào, tiếp xúc và phản ứng đầu tiên với các chất có độc tính, đồng thời có khả năng phân chia và biệt hóa in vitro tốt nên được lựa chọn trong nghiên cứu này. Dòng tế bào này là quà tặng của GS.TS. Ulrike Lindequist, Đại học Greifswald, Cộng hòa Liên bang Đức. Các dịch chiết từ 9 loài thực vật thu thập được ở Việt Nam, được biết có tác dụng chữa bệnh trong dân gian (bảng 1).

Bảng 1 . Danh sách thực vật sử dụng trong nghiên cứu và bộ phận sử dụng

\begin{tabular}{|c|l|l|c|}
\hline STT & Tên Việt Nam & \multicolumn{1}{|c|}{ Tên khoa học } & Bộ phận sử dụng \\
\hline 1 & Nụ vối & Cleistocalyx operculatus & Buds \\
\hline 2 & Xoài & Mangifera indica & Leaves \\
\hline 3 & Xuân Hoa & Pseuderanthemum palatiferum & Leaves \\
\hline 4 & Lá Lốt & Piper lolot & Leaves \\
\hline 5 & Trầu không & Piper betle & Leaves \\
\hline 6 & Sim & Rhodomyrtus tomentosa & Leaves \\
\hline 7 & Măng cụt & Garcinia mangostana & Fruit Skin \\
\hline 8 & Tai chua & Garcinia cowa & Fruit \\
\hline 9 & Bàng & Terminalia catappa & Leaves \\
\hline
\end{tabular}

Chín loài thực vật này được thu tại một số tỉnh phía Bắc Việt Nam và được phân loại tại Viện Sinh thái và Tài nguyên sinh vật, Viện Hàn lâm Khoa học và Công nghệ Việt Nam. Các dịch chiết được chuẩn bị như sau: nguyên liệu thực vật sấy khô ở $60^{\circ} \mathrm{C}$ và xay thành bột mịn $(10 \mathrm{~g})$ được chiết lần lượt với $400 \mathrm{ml}$ hexane trong 8 giờ, sau đó được chiết tiếp bằng $400 \mathrm{ml}$ methanol $(\mathrm{MeOH})$ trong 8 giờ sử dụng thiết bị Soxhlet. Việc chiết xuất được lặp lại hai lần và sau đó được sấy khô để thu nhận cao hexane và methanol sử dụng máy cô cất quay chân không. 


\section{Độc tính tế bào}

Ảnh hưởng của dịch chiết đến độ sống của tế bào được xác định bằng phương pháp MTT. Tế bào được nuôi cấy trong môi trường DMEM trong đĩa 96 giếng ở mật độ $5 \times 10^{3}$ tế bào/giếng và bổ sung hàm lượng khác nhau của các chất cần nghiên cứu, hoặc không bổ sung những chất này để làm đối chứng. Khả năng sống sót của tế bào được xác định thông qua giá trị $\mathrm{IC}_{50}(50 \%$ quần thể tế bào còn sống sót) (Riss et al., 2004). Ngoài ra, các giá trị $\mathrm{IC}_{10}(10 \%$ quần thể tế bào còn sống sót $)$ và $\mathrm{IC}_{25}$ (25\% quần thể tế bào còn sống sót) cũng được xác định để làm cơ sở cho các nghiên cứu về ảnh hưởng của các chất này lên sự sinh gốc oxi nội bào và chu trình tế bào ở các thí nghiệm sau. Các thí nghiệm được lặp lại 3 lần.

\section{Xác định hoạt tính chống oxi hóa bằng DPPH}

Hoạt tính chống oxi hóa của dịch chiết được xác định định tính bằng phương pháp sắc ký lớp mỏng trên bản nhôm tráng sẵn (Merck) sau đó phun hóa chất 2,2-Diphenyl1-picrylhydrazyl (DPPH) hoặc định lượng bằng $\mathrm{DPPH}$ theo phương pháp đo quang phồ. Sự thay đổi của nồng độ DPPH bởi các chất chống oxi hóa được xác định bằng cách đo độ hấp thụ tại $\mathrm{A}_{517}$. Axit ascorbic được sử dụng làm chất đối chứng dương (Tailor \& Anju, 2014).

\section{Xác định các loại oxi phản ứng nội bào}

Để xác định các loại oxi phản ứng nội bào gồm các gốc hydroxyl hoặc các gốc peroxyl, thuốc nhuộm diacetate 2',7'dichlorodihydrofluorescein (H2DCFDA) đã được sử dụng. Do tính chất không phân cực, H2DCFDA khuếch tán vào bên trong tế bào và tương tác với các este nội bào để tạo thành H2DCF có tính phân cực nên không thể rời khỏi bên trong tể bào. Sự hiện diện của các gốc oxi phản ứng nội bào sẽ khiến DCF (2',7'-dichlorofluorescein) bi oxi hóa cho huỳnh quang xanh. Cường độ huỳnh quang tương quan với lượng iROS được hình thành và được định lượng trên máy đo dòng chảy (Wang và Joseph, 1999). Dung dịch tế bào
$4 \times 10^{5} / 2 \mathrm{ml}$ được cấy vào các đĩa nuôi cấy tế bào, được ủ trong tủ ấm và xử lý với các dịch chiết trong 72 giờ, sau đó được kích thích tiếp với dung dịch hydroperoxyde $4 \mathrm{mM}$ tert-butyl (dung dịch TBH) trong 1 giờ. Trong mỗi trường hợp, nồng độ của $\mathrm{IC}_{50}, \mathrm{IC}_{25}, \mathrm{IC}_{10}$ sẽ được thử nghiệm. Huỳnh quang được đo ngay trên máy đo dòng chảy. Kết quả thu được sau đó đã được đánh giá bằng phần mềm Kaluza®.

\section{Phân tích chu kỳ tế bào}

Sự phân bố của các tế bào trong các giai đoạn chu kỳ tế bào riêng lẻ có thể được xác định sử dụng propidium iodide (PI). PI có khả gắn vào các axit nucleic sợi đôi do đó cường độ huỳnh quang tỷ lệ thuận với hàm lượng DNA trong tế bào. Để phân tích chu kỳ tế bào, dung dịch tế bào mật độ $4 \times 10^{5}$ tế bào $/ 2 \mathrm{ml}$ được cấy vào các đĩa nuôi cấy tế bào 24 giếng và được ủ trong tủ ấm $37^{\circ} \mathrm{C}$ trong 24 giờ. Sau đó, môi trường được loại bỏ và thêm vào với $2 \mathrm{~mL}$ dịch chiết với độ pha loãng chiết tương ứng cho $\mathrm{IC}_{50}, \mathrm{IC}_{25}$ và $\mathrm{IC}_{10}$. Sau 72 giờ ủ, các tế bào ở mỗi mẫu nghiên cứu sẽ được được thu lại và đo trên máy đếm tế bào có mặt của $10 \mu \mathrm{L}$ propidium iodide $1 \mathrm{mg} / \mathrm{mL}$. Việc đánh giá dữ liệu được thực hiện với sự trợ giúp của Phần mềm Kaluza®.

\section{KÊTT QUẢ VÀ THẢO LUẬN}

\section{Độc tính gây độc của chiết xuất thực vật}

Kết quả về hoạt tính gây độc của các dịch chiết nghiên cứu trong $\mathrm{MeOH}$ và Hexane được trình bày trong bảng 2 và bảng 3 .

Có thể thấy tất cả các dịch chiết hexane đều gây độc tế bào, đặc biệt là các dịch chiết của ba loài thực vật $G$. mangostana, $P$. lolot và $R$. tomentosa với $\mathrm{IC}_{50}$ đạt $14,27 \mu \mathrm{g} / \mathrm{mL}$, $26,37 \mu \mathrm{g} / \mathrm{mL}$ và $39,36 \mu \mathrm{g} / \mathrm{mL}$, theo thứ tự. Các giá trị của $\mathrm{IC}_{10}, \mathrm{IC}_{25}$ và $\mathrm{IC}_{50}$ của dịch chiết hexane của $G$. mangostana tương đương với của dịch chiết $\mathrm{MeOH}$. Đáng chú ý, độc tính tế bào của dịch chiết $C$. operculatus và $P$. lolot lần đầu tiên được thực hiện trong nghiên cứu này. Số liệu ở bảng 4 cho thấy, dịch chiết hexane có độc tính tế bào manh hơn so với dịch chiết $\mathrm{MeOH}$ từ 2 đến 10 lần. 
Bảng 2. Độc tính tế bào của các dịch chiết MeOH trên dòng tế bào HaCaT-Keratinocyte (MTTtest, 72 giờ $) \pm \mathrm{SD}, \mathrm{n}=5$

\begin{tabular}{|l|c|c|c|}
\hline \multicolumn{1}{|c|}{ Dịch chiết $\mathrm{MeOH}$} & $\mathrm{IC}_{50}(\mu \mathrm{g} / \mathrm{mL})$ & $\mathrm{IC}_{25}(\mu \mathrm{g} / \mathrm{mL})$ & $\mathrm{IC}_{10}(\mu \mathrm{g} / \mathrm{mL})$ \\
\hline Garcinia mangostana & $14,42 \pm 1,33$ & $11,92 \pm 1,41$ & $10,63 \pm 1,43$ \\
\hline Piper betle & $91,77 \pm 11,11$ & $73,03 \pm 10,31$ & $63,72 \pm 10,01$ \\
\hline Rhodomyrtus tomentosa & $117,93 \pm 12,08$ & $90,64 \pm 10,05$ & $77,43 \pm 9,18$ \\
\hline Cleistocalyx operculatus & $119,98 \pm 4,63$ & $95,77 \pm 4,42$ & $83,65 \pm 4,27$ \\
\hline Terminalia catappa & $122,08 \pm 17,90$ & $78,18 \pm 11,78$ & $59,95 \pm 10,22$ \\
\hline Mangifera indica & $124,90 \pm 11,11$ & $102,41 \pm 11,06$ & $90,93 \pm 10,88$ \\
\hline Piper lolot & $266,63 \pm 48,15$ & $226,13 \pm 45,53$ & $205,60 \pm 47,25$ \\
\hline Pseuderanthemum palatiferum & $308,35 \pm 25,77$ & $269,29 \pm 22,00$ & $248,28 \pm 20,01$ \\
\hline Garcinia cowa & $>500$ & $>500$ & $>500$ \\
\hline
\end{tabular}

Bảng 3. Độc tính tế bào của các dịch chiết hexane trên dòng tế bào HaCaT-Keratinocyte, (MTT-test, 72 giờ) $\pm \mathrm{SD}, \mathrm{n}=5$

\begin{tabular}{|l|c|c|c|}
\hline \multicolumn{1}{|c|}{ Dịch chiết Hexane } & $\mathrm{IC}_{50}(\mu \mathrm{g} / \mathrm{mL})$ & $\mathrm{IC}_{25}(\mu \mathrm{g} / \mathrm{mL})$ & $\mathrm{IC}_{10}(\mu \mathrm{g} / \mathrm{mL})$ \\
\hline Garcinia mangostana & $14,27 \pm 1,47$ & $11,76 \pm 1,64$ & $10,48 \pm 1,69$ \\
\hline Piper lolot & $26,37 \pm 3,44$ & $20,17 \pm 1,62$ & $17,20 \pm 1,31$ \\
\hline Rhodomyrtus tomentosa & $39,36 \pm 5,75$ & $23,35 \pm 4,35$ & $17,08 \pm 3,62$ \\
\hline Piper betle & $59,60 \pm 8,93$ & $41,86 \pm 8,62$ & $33,91 \pm 8,11$ \\
\hline Cleistocalyx operculatus & $64,50 \pm 5,87$ & $47,97 \pm 5,16$ & $40,18 \pm 4,80$ \\
\hline Mangifera indica & $83,57 \pm 3,03$ & $45,36 \pm 3,48$ & $31,46 \pm 3,16$ \\
\hline Pseuderanthemum palatiferum & $>500$ & $277,62 \pm 25,24$ & $147,97 \pm 11,4$ \\
\hline
\end{tabular}

Bảng 4. So sánh các giá trị $\mathrm{IC}_{50}$ giữa dịch chiết $\mathrm{MeOH}$ và hexane

\begin{tabular}{|l|c|c|}
\hline \multicolumn{1}{|c|}{ Thực vật } & $\mathrm{MeOH}_{\mathrm{IC}}$ & $\mathrm{Hexane}_{50} \mathrm{IC}_{50}$ \\
\hline Garcinia mangostana & $14,42 \pm 1,33$ & $14,27 \pm 1,47$ \\
\hline Piper lolot & $266,63 \pm 48,15$ & $26,37 \pm 3,44$ \\
\hline Rhodomyrtus tomentosa & $117,93 \pm 12,08$ & $39,36 \pm 5,75$ \\
\hline Piper betle & $91,77 \pm 11,11$ & $59,60 \pm 8,93$ \\
\hline Cleistocalyx operculatus & $119,98 \pm 4,63$ & $64,50 \pm 5,87$ \\
\hline Mangifera indica & $124,90 \pm 11,11$ & $83,57 \pm 3,03$ \\
\hline Pseuderanthemum palatiferum & $308,35 \pm 25,77$ & $>500$ \\
\hline
\end{tabular}

Hoạt tính triệt tiêu gốc tự do DPPH của các dịch chiết thực vật

Trong thí nghiệm sàng lọc sử dụng sắc ký lớp mỏng nhằm tìm hiểu tiềm năng chống oxi hóa của các dịch chiết từ thực vật. Bản sắc ký sau khi phun bằng thuốc thử $\mathrm{DPPH}$ đã có sự đổi màu của các dịch chiết $\mathrm{MeOH}$ của $C$. operculatus $(1 \mathrm{M}), \quad M$. indica $(2 \mathrm{M}), \quad P$. palatiferum (3M), P. betle (5M), R. tomentosa (6M), G. mangostana (7M), T. catappa (9M) và chiết xuất hexane của $P$. betle $(5 \mathrm{H}), G$. mangostana $(7 \mathrm{H})$. Trong khi đó, các dịch chiết $\mathrm{MeOH}$ của $P$. lolot $(4 \mathrm{M})$ và $G$. cowa
(8M) cũng như hexane của $P$. palatiferum $(3 \mathrm{H})$ và $P$. lolot $(4 \mathrm{H})$ không bị đổi màu, gợi ý các dịch chiết này không có khả năng triệt tiêu gốc tự do (hình 1). Các dịch chiết thực vật có hoạt tính tiếp tục được đánh giá hoạt tính chống oxi hóa trong khoảng nồng độ 10-500 $\mu \mathrm{g} / \mathrm{mLvà} \mathrm{xác} \mathrm{định} \mathrm{khả} \mathrm{năng} \mathrm{triệt} \mathrm{tiêu} 50 \%$ các gốc tự do $\left(\mathrm{EC}_{50}\right)$. Tuy nhiên, không có dịch chiết nào cho thây có khả năng chống oxi hóa mạnh hơn chất đối chứng dương là axit ascorbic. Các số liệu trình bày trong bảng 5 cho thấy dịch chiết của $C$. operculatus (C.o.), $M$. indica (M.i.) và $T$. catappa (T.c.) có khả 
năng chống oxi hóa mạnh tương tự như axit ascoribic. P. betle (P.b.) và G. mangostana (G.m.) có $\mathrm{EC}_{50}$ đạt $59,93 \mu \mathrm{g} / \mathrm{mL}$ và 58.10 $\mu \mathrm{g} / \mathrm{mL}$, gần bằng $\mathrm{EC}_{50}$ của axit ascoribic. Các dịch chiêt khác chỉ đạt được hiệu quả tương ứng với axit ascoribic ở nồng độ $500 \mu \mathrm{g} / \mathrm{mL}$.

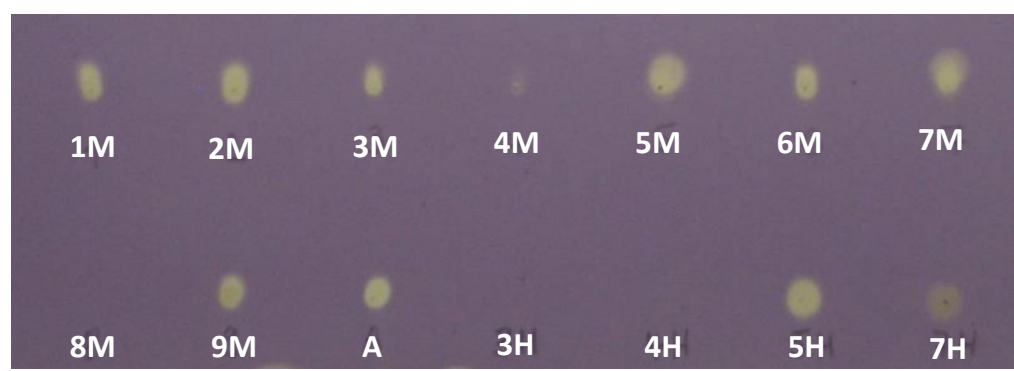

Hình 1. Hoạt tính chống oxi hóa của các dịch chiết $\mathrm{MeOH}$ sử dụng DPPH. Cleistocalyx operculatus (1M), Mangifera indica (2M), Pseuderanthemum palatiferum (3M), Piper lolot $(4 \mathrm{M})$, Piper betle (5M), Rhodomyrtus tomentosa (6M), Garcinia mangostana (7M), Garcinia cowa $(8 \mathrm{M})$, Terminalia catappa $(9 \mathrm{M})$; Dịch chiết hexane: Pseuderanthemum palatiferum $(3 \mathrm{H})$, Piper lolot (4H), Piper betle (5H), Garcinia mangostana (7H). Axit ascorbic (A)

Bảng 5. Khả năng chống oxi hóa của các dịch chiết thực vật. $\mathrm{TB} \pm \mathrm{SD}, \mathrm{n}=3$; Axit ascorbic (As), C. operculatus (C.o.), M. indica (M.i.), P. palatiferum (P.p.), P. betle (P.b.), G. mangostana (G.m.), T. catappa

\begin{tabular}{|l|c|c|c|c|c|c|}
\hline \multirow{7}{*}{ Samples } & \multicolumn{7}{|c|}{ Concentration $(\mu \mathrm{g} / \mathrm{mL})$} & \multirow{2}{*}{$\begin{array}{c}\text { EC } 50 \\
\end{array}$} & 10 & 50 & 100 & 500 & 1000 & $(\mu \mathrm{g} / \mathrm{mL})$ \\
\hline As & $50,94 \pm 0,94$ & $96,02 \pm 0,37$ & $96,09 \pm 0,35$ & $96,09 \pm 0,35$ & $96,23 \pm 0,32$ & $\mathbf{9 , 1 5} \pm \mathbf{0 , 8 6}$ \\
\hline MeOH & $20,97 \pm 2,11$ & $87,70 \pm 2,47$ & $94,32 \pm 1,21$ & $92,14 \pm 1,70$ & $90,56 \pm 7,39$ & $\mathbf{2 7 , 4 0} \pm \mathbf{0 , 0 7}$ \\
\hline C.o. & $29,61 \pm 1,82$ & $92,28 \pm 0,22$ & $94,51 \pm 1,28$ & $92,17 \pm 3,39$ & $90,11 \pm 8,63$ & $\mathbf{2 3 , 0 0} \pm \mathbf{0 , 7 4}$ \\
\hline M.i. & $17,29 \pm 20,18$ & $43,97 \pm 9,10$ & $66,73 \pm 7,83$ & $88,55 \pm 0,38$ & $93,20 \pm 12,12$ & $\mathbf{9 4 , 3 0} \pm \mathbf{3 6 , 2 0}$ \\
\hline P.p. & $8,91 \pm 0,44$ & $49,12 \pm 10,65$ & $79,73 \pm 15,25$ & $88,37 \pm 4,87$ & $84,12 \pm 9,94$ & $\mathbf{5 9 , 9 3} \pm \mathbf{1 2 , 3 5}$ \\
\hline P.b. & $11,53 \pm 1,20$ & $52,23 \pm 11,02$ & $78,50 \pm 14,48$ & $93,95 \pm 1,30$ & $93,40 \pm 1,40$ & $\mathbf{5 8 , 1 0} \pm \mathbf{1 3 , 0 5}$ \\
\hline G.m. & \multicolumn{7}{|c|}{} \\
\hline Hexane & \multicolumn{7}{|c|}{} \\
\hline T.c. & $29,00 \pm 3,11$ & $90,33 \pm 4,63$ & $94,03 \pm 0,25$ & $93,32 \pm 1,86$ & $92,39 \pm 4,47$ & $\mathbf{2 3 , 7 3} \pm \mathbf{2 , 3 7}$ \\
\hline P.b. & $4,33 \pm 2,23$ & $42,07 \pm 2,25$ & $76,81 \pm 5,10$ & $92,10 \pm 4,10$ & $89,38 \pm 8,72$ & $\mathbf{6 4 , 5 8} \pm \mathbf{4 , 4 5}$ \\
\hline G.m. & $-3,21 \pm 1,96$ & $12,70 \pm 1,39$ & $28,13 \pm 3,96$ & $91,65 \pm 2,31$ & $90,29 \pm 5,96$ & $\mathbf{2 6 2 , 4 0} \pm \mathbf{1 , 6 5}$ \\
\hline
\end{tabular}

\section{Khả năng triệt tiêu gốc tự do hydroxyl/peroxyl}

Kết quả thu được cho thấy, khi ủ các tế bào với các dịch chiết nghiên cứu đều có sự tăng sinh các gốc oxi tự do (iROS) hydroxyl/peroxyl nội bào được kích thích bằng TBH (số liệu không trình bày). $M$. indica ở nồng độ $\mathrm{IC}_{10}$ đã kích thích tạo gốc $\mathrm{iROS}$ sau khi xử lý thêm với $\mathrm{TBH}$ và làm tăng lượng iROS khoảng $20 \%$, trong khi G. mangostana và $T$. catappa lại làm giảm iROS (số liệu không trình bày). Phát hiện này cũng được thông báo trong một số nghiên cứu trước đây (Tsai et al., 2016; Moongkarndi et al., 2004;
Huang et al., 2018). Sự ức chế iROS của G.mangostana và $T$. catappa khác biệt đáng kể ở nồng độ sử dụng $\mathrm{IC}_{25}$ và $\mathrm{IC}_{50}$. Đây là phát hiện khá thú vị khi các dịch chiết này vừa có hoạt tính triệt tiêu gốc tự do mạnh lại vừa có khả năng gây độc tế bào cao. Như vậy, hoạt tính gây độc tế bào của các dịch chiết này có thể liên quan đến một/một số cơ chế gây độc tế bào khác, thí dụ như tương tác màng, ức chế các enzyme chìa khóa liên quan đên quá trình trao đổi chất trong tế bào chất, hay cảm ứng quá trình apoptosis... Số liệu trong bảng 6 cho thấy, mặc dù nhiều dịch chiết từ thực vật có hoạt tính chống oxi hóa trong thử nghiệm với DPPH nhưng lại không được phát 
hiện bằng phương pháp nhuộm huỳnh quang tế bào. Về nguyên tắc, hai phương pháp này không thể so sánh với nhau do các điều kiện thực hiện phản ứng diễn ra khác nhau. Thử nghiệm DPPH là thuần túy hóa học, không xảy ra trong tế bào. Trong khi đó, thử nghiệm sử dụng tế bào với thuốc nhuộm huỳnh quang H2DCFDA, cho phép hyperoxyde và hydroxyl được phát hiện.

\section{Ảnh hưởng đến chu kỳ tế bào của các dịch} chiết

Kết quả ảnh hưởng của các dịch chiết $\mathrm{MeOH}$ đên chu kỳ tế bào hình 2 và bảng 6 đã các dịch chiết của $T$. catappa, R. tomentosa, $M$. indica và $P$. betle ở nồng độ
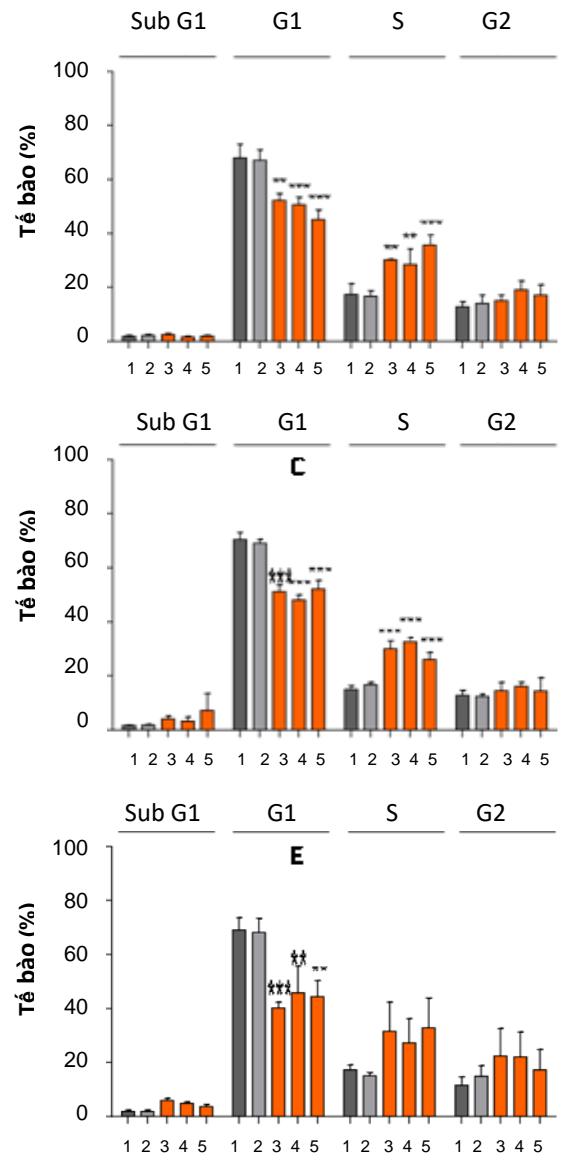

$\mathrm{IC}_{10}$ đã có tác dụng mạnh đến chu trình tế bào thông qua việc làm giảm số lượng tế bào trong pha G1. Tất cả các dịch chiết từ thực vật đều cho thấy có sự gia tăng trong số lượng tế bào trong pha $\mathrm{S}$ hoặc $\mathrm{G} 2 / \mathrm{M}$ nhưng gần như không thấy có sự tăng số lượng tế bào trong pha subG1. Điều này cho thây đã có sự kháng phân bào (cell cycle arrest) trong pha $\mathrm{S}$ hoặc G2/M. Sự kháng phân bào trong pha G2/M dẫn đến việc làm chậm quá trình phân chia mitosis, làm cảm ứng quá trình apoptosis, tăng độc tính tế bào (Di Paola, 2002). Phát hiện này cũng đã được thông báo với các xanthone trong dịch chiết $G$. mangostana trước đây (Matsumoto et al., 2005; Moongkarndi et al., 2004).
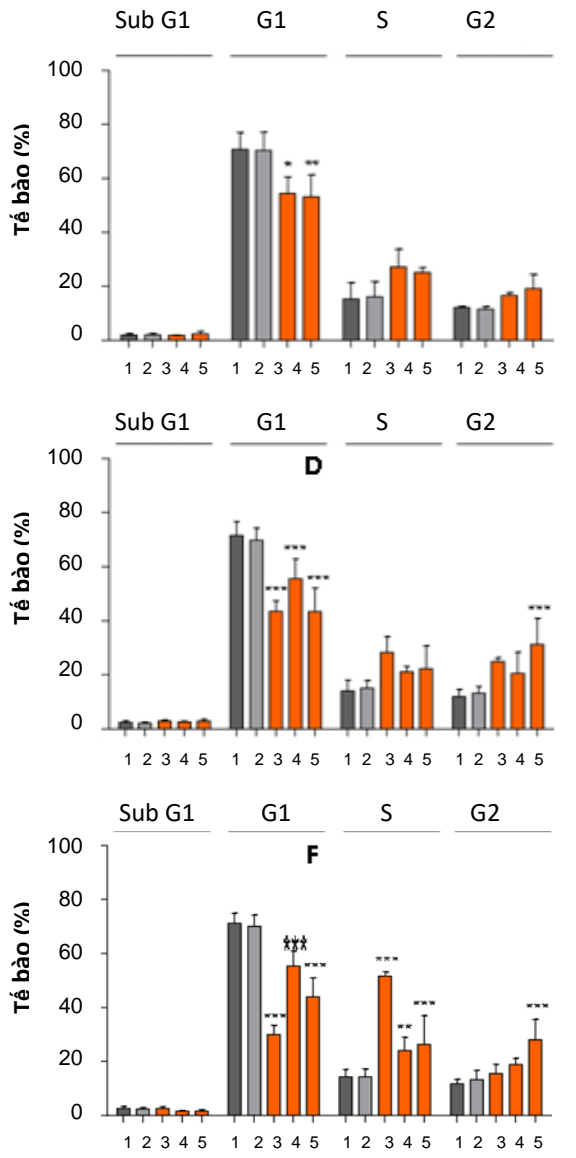

Hình 2. Phân tích chu kỳ tế bào HaCaT sau 72 giờ xử lý với các chiết xuất methanol khác nhau.

A: Garcinia mangostana, B: Cleistocalyx operculatus; C: Rhodomyrtus tomentosa, D:

Mangifera indica, E: Piper betle, F: Terminalia catappa; 1 . các tế bào không xử lý; 2 . các tế bào được xử lý bằng $\mathrm{MeOH} ; 3 . \mathrm{IC}_{10} ; 4 . \mathrm{IC}_{25} ; 5 . \mathrm{IC}_{50} ; \mathrm{n}=3$, * $\mathrm{p}<0,05$, ** $\mathrm{p}<0,01$, *** $\mathrm{p}<0,001$ so với dung môi $\mathrm{MeOH}$ 
Bảng 6. Ảnh hưởng của dịch chiết $\mathrm{MeOH}$ đến chu kỳ tế bào và giảm iROS được kích thích bằng

TBH (Tăng: $\uparrow \mathrm{p}<0,05, \uparrow \uparrow \mathrm{p}<0,01, \uparrow \uparrow \uparrow \mathrm{p}<0,001$; giảm: $\downarrow \mathrm{p}<0,05, \downarrow \downarrow \mathrm{p}<0,01, \downarrow \downarrow \downarrow \mathrm{p}<$

0,$001 ;(\uparrow)$ tăng không đáng kể; $(\downarrow)$ giảm không đáng kể $(\varnothing)$; Không thay đổi đáng kể)

\begin{tabular}{|c|c|c|c|c|c|c|}
\hline \multirow{2}{*}{ Plants } & \multirow{2}{*}{ Concentration } & \multicolumn{4}{|c|}{ Phases in cell cycle } & \multirow{2}{*}{$\begin{array}{c}\text { Level of iROS } \\
\text { scavenge }\end{array}$} \\
\hline & & subG $_{1}$ & $\mathrm{G}_{1}$ & $\mathrm{~S}$ & $\mathrm{G}_{2} / \mathrm{M}$ & \\
\hline \multirow{2}{*}{ Cleistocalyx operculatus } & $\mathrm{IC}_{25}$ & $\varnothing$ & $\downarrow$ & $(\uparrow)$ & $(\uparrow)$ & $\varnothing$ \\
\hline & $\mathrm{IC}_{50}$ & $\varnothing$ & $\downarrow \downarrow$ & $(\uparrow)$ & $(\uparrow)$ & $\varnothing$ \\
\hline \multirow{3}{*}{ Mangifera indica } & $\mathrm{IC}_{10}$ & $\varnothing$ & $\downarrow \downarrow \downarrow$ & $(\uparrow)$ & $(\uparrow)$ & $\varnothing$ \\
\hline & $\mathrm{IC}_{25}$ & $\varnothing$ & $\downarrow \downarrow \downarrow$ & $(\uparrow)$ & $(\uparrow)$ & $\varnothing$ \\
\hline & $\mathrm{IC}_{50}$ & $\varnothing$ & $\downarrow \downarrow \downarrow$ & $(\uparrow)$ & $\uparrow \uparrow \uparrow$ & $\varnothing$ \\
\hline \multirow{3}{*}{ Piper betle } & $\mathrm{IC}_{10}$ & $(\uparrow)$ & $\downarrow \downarrow \downarrow$ & $(\uparrow)$ & $(\uparrow)$ & $\varnothing$ \\
\hline & $\mathrm{IC}_{25}$ & $\varnothing$ & $\downarrow \downarrow$ & $(\uparrow)$ & $(\uparrow)$ & $(\uparrow)$ \\
\hline & $\mathrm{IC}_{50}$ & $\varnothing$ & $\downarrow \downarrow$ & $(\uparrow)$ & $\varnothing$ & $(\uparrow)$ \\
\hline \multirow{3}{*}{ Rhodomyrtus tomentosa } & $\mathrm{IC}_{10}$ & $\varnothing$ & $\downarrow \downarrow \downarrow$ & $\uparrow \uparrow \uparrow \uparrow$ & $\varnothing$ & $\varnothing$ \\
\hline & $\mathrm{IC}_{25}$ & $\varnothing$ & $\downarrow \downarrow \downarrow$ & $\uparrow \uparrow \uparrow \uparrow$ & $\varnothing$ & $\varnothing$ \\
\hline & $\mathrm{IC}_{50}$ & $(\uparrow)$ & $\downarrow \downarrow \downarrow$ & $\uparrow \uparrow \uparrow \uparrow$ & $\varnothing$ & $(\uparrow)$ \\
\hline \multirow{3}{*}{ Garcinia mangostana } & $\mathrm{IC}_{10}$ & $\varnothing$ & $\downarrow \downarrow$ & $\uparrow \uparrow$ & $\varnothing$ & $\downarrow$ \\
\hline & $\mathrm{IC}_{25}$ & $\varnothing$ & $\downarrow \downarrow \downarrow$ & $\uparrow \uparrow$ & $(\uparrow)$ & $\downarrow$ \\
\hline & $\mathrm{IC}_{50}$ & $\varnothing$ & $\downarrow \downarrow \downarrow$ & $\uparrow \uparrow \uparrow \uparrow$ & $\varnothing$ & $\downarrow$ \\
\hline \multirow{3}{*}{ Terminalia catappa } & $\mathrm{IC}_{10}$ & $\varnothing$ & $\downarrow \downarrow \downarrow$ & $\uparrow \uparrow \uparrow \uparrow$ & $\varnothing$ & $\varnothing$ \\
\hline & $\mathrm{IC}_{25}$ & $\varnothing$ & $\downarrow \downarrow \downarrow$ & $\uparrow \uparrow$ & $(\uparrow)$ & $\downarrow \downarrow \downarrow$ \\
\hline & $\mathrm{IC}_{50}$ & $\varnothing$ & $\downarrow \downarrow \downarrow$ & $\uparrow \uparrow \uparrow \uparrow$ & $\uparrow \uparrow \uparrow \uparrow$ & $\downarrow \downarrow$ \\
\hline
\end{tabular}

\section{KẾT LUẬN}

Các dịch chiết thực vật được nghiên cứu có tác dụng gây độc tế bào HaCaT. Dịch chiết hexane có độc tính tế bào cao hơn so với dịch chiết methanol. Các dịch chiết từ bốn loài thực vật $T$. catappa, R. tomentosa, $M$. indica và $P$. betle có tác dụng mạnh đến chu trình tế bào thông qua việc làm giảm số lượng tế bào trong pha $\mathrm{G} 1$ và gia tăng số lượng tế bào trong pha $\mathrm{S}$ hoặc $\mathrm{G} 2 / \mathrm{M}$, điều này gợi ý có sự kháng phân bào trong pha $\mathrm{S}$ hoặc G2/M. Nghiên cứu sâu hơn về cơ chế gây độc và hoạt tính kháng phân bào của các dịch chiết này cũng như các chất có trong dịch chiết cần được tiếp tục để làm sáng tỏ cơ chế tác dụng và ứng dụng của chúng.

Lời cảm ơn: Công trình này được hoàn thành với sự tài trợ một phần kinh phí từ cơ quan Trao đổi Hàn lâm Đức (DAAD) năm 2015 và từ đề tài NAFOSTED mã số 106-NN.022016.19.

\section{TÀI LIỆU THAM KHẢO}

Abdullah A. H., Mohammed A. S., A. R., Mirghani M. E. S., Al-Qubaisi M., 2014. Cytotoxyc effects of Mangifera indica $\mathrm{L}$. kernel extract on human breast cancer (MCF-7 and MDA-MB-231cell lines) and bioactive constituents in the crude extract. BMC Compl. Altern. Med, 14: 199.

Abrahim N. N., Kanthimathi M. S., AbdulAziz A., 2012. Piper betle shows antioxydant activities, inhibits MCF-7 cell proliferation and increases activities of catalase and superoxyde dismutase. BMC Compl. Altern. Med, 12: 220.

Behera D. R., Bhatnagar S., Mahapatra A. K., 2013. Cytotoxyc and radical scavenging potential of Indian almond (Terminalia catappa) leaf extracts. British Biomed. Bull, 1: 31-39.

Di Paola R. S., 2002. To arrest or not to G2-M cell cycle arrest. Clin. Cancer Res., 8: 3311-3314.

Dosoky N. S., Pokharel S. K., Setzer W. N., 2015. Leaf essential oil composition, antimicrobial and cytotoxyc activities of Cleistocalyx operculatus from Hetauda, Nepal. American J. Essent. Oil Nat.Prod., 3(1): 34-37. 
Do Tat Loi, 1991. Medicinal plants and herbs of Vietnam, Medical publishing house.

Huang Y. H., Wu P. Y., Wen K. C., Lin C. Y., Chiang H. M., 2018. Protective effects and mechanisms of Terminalia catappa $\mathrm{L}$. methenolic extract on hydrogen-peroxydeinduced oxydative stress in human skin fibroblasts. BMC Complement. Altern. Med, 18(1): 266.

Li C. Y., Tsai W. J., Damu A. G., Lee E. J., Wu T. S., Dung N. X., 2007. Isolation and identification of antiplatelet aggregatory principles from the leaves of Piper lolot. J. Agr. food Chem., 55(23): 9436-9442.

Mahabusarakam W., Chairerk P., Taylor W. C., 2005. Xanthones from Garcinia cowa Roxb. latex. Phytochemistry, 66(10): 1148-1153.

Moongkarndi P., Kosem N., Kaslungka S., Luanratana O., Pongpan N., Neungton N., 2004, Antiproliferation, antioxydation and induction of apoptosis by Garcinia mangostana (mangosteen) on SKBR3 human breast cancer cell line. $J$. Ethnopharmacol, 90(1): 161-166.

Matsumoto K., Akao Y., Ohguchi K., Ito T., Tanaka T., Iinuma M., Nozawa Y., 2005. Xanthones induce cell-cycle arrest and apoptosis in human colon cancer DLD-1 cells. Bioorg. Med. Chem., 13(21): 6064-6069.

Padmapriya N., Poonguzhali T. V., 2015. Antioxydant potential from the acetone extractstem and leaves of Piper betle. IJAR, 19-22.
Saraiva dos R., 2012. An in vitro analysis of the total phenolic content, antioxydant power, physical, physicochemical, and chemical composition of Terminalia catappa Linn fruits. Sci. Technol. Aliment, 32(1): 209-213.

Riss T. L., Moravec R. A., Niles A. L., Benink H. A., Worzella T. J., Minor L., 2004. Cell viability assays. In Assay Guidance Manual. Bethesda (MD).

Tailor C. S., Anju G., 2014. Antioxydant activity by DPPH radical scavenging method of Ageratum conyzoides Linn. leaves. American J. Ethnol: 244-249.

Tandon V., Gupta B. M., 2005. Free radicals/reactive oxygen species. JKPractitioner: $143-148$.

Tsai S. Y., Chung P. C., Owaga E. E., Tsai I. J., Wang P. Y., Tsai J. I., Yeh T. S., and Hsieh R. H., 2016. Alpha-mangostin from mangosteen (Garcinia mangostana Linn.) pericarp extract reduces high fat-diet induced hepatic steatosis in rats by regulating mitochondria function and apoptosis. Nutr. Metab. (Lond), 13: 88.

Wang H., Joseph J. A., 1999. Quantifying cellular oxydative stress by dichlorofluorescein assay using microplate reader. Free Rad. Boil. Med., 27(5-6): 612-616.

Wu P., Ma G., Li N., Deng Q., Yin Y., Huang R., 2015. Investigation of in vitro and in vivo antioxydant activities of flavonoids rich extract from the berries of Rhodomyrtus tomentosa (Ait.) Hassk. Food Chem., 173: 194-202. 